\title{
ESTIMULAR O EMPREENDEDORISMO NA TERCEIRA IDADE
}

Originais recebidos em: 22/09/2011

Aceito para publicação em: 21/12/2011

Ana Lucia Ferraresi Schmitz Universidade Federal de Santa Catarina alf@ccs.ufsc.br

Edis Mafra Lapolli Universidade Federal de Santa Catarina edismafra@gmail.com

Francisco José Bernardes

Universidade Federal de Santa Catarina joseber@reitoria.ufsc.br

\section{Resumo}

$\mathrm{O}$ artigo aborda um estudo de caso com pessoas da terceira idade inseridas no Programa do Núcleo de Estudos da Terceira Idade da Universidade Federal de Santa Catarina (NETI/UFSC). O estudo foi realizado entre os anos 2008 e 2009 e contou com 24 participantes. Objetivou despertar capacidades empreendedoras nos participantes, a partir de suas habilidades pessoais, por meio da aplicação de aulas participativas, visando ao aprimoramento da teoria e da prática empreendedora na terceira idade. Os métodos utilizados passaram por adaptações necessárias para o tipo de público, incluindo aulas expositivas, projeção de vídeos e dinâmicas vivenciais. O resultado foi alcançado, tendo em vista a avaliação positiva feita pelos participantes no questionário aplicado no início e no final das atividades didáticas de cada curso. Evidenciou-se a importância do estímulo para o empreendedorismo nessa faixa etária, visto que os participantes apresentaram alteração das atitudes de participação e predisposição para a inovação. A proatividade ficou estampada no comportamento pessoal com definição de metas e relato de sonhos empreendedores.

Palavras chaves: Empreendedorismo. Capacidade empreendedora. Terceira idade.

ENTREPRENEURSHIP STIMULATE IN THE ELDERLY

\begin{abstract}
The article approaches a case study with people of the third age inserted in the Program Nucleus of Studies of the Third Age - Federal University of Santa Catarina (NETI/UFSC), among the years 2008 and 2009, with a total of 24 participants. Had the objective of waking up enterprising capacities in the participants, starting from your personal abilities, through the application of classes to participate, seeking to perfect of the theory and of the enterprising practice in the third age. The used methods went by necessary adaptations for the type of participant public, including classes expose, projection of videos and dynamics lives. The result was reached tends in view the positive evaluation of the course done by the participants through applied questionnaire in the beginning and in the end of the didactic activities of each course. Highlighted the importance of the stimulus for the next entrepreneur in this age group, which eventually produce change in attitudes to participation and predisposition for innovation. The participation was printed in the personal behavior with definition of goals and report of enterprising dreams.
\end{abstract}

Keywords: Entrepreneurship. Ability Entrepreneur. Third Age. 


\section{CONSIDERAÇÕES INICIAIS}

As diversas mudanças no cenário socioeconômico vêm repercutindo na vida e na estabilidade das pessoas, em particular, no grupo etário da terceira idade, com relação ao estímulo e ao desafio de uma vida mais ativa. Para lidar com o novo cenário, esse grupo etário precisa saber lidar com as dificuldades e fazer delas suas aliadas, procurando descobrir habilidades até então escondidas. O empreendedorismo surge como uma ferramenta eficaz para esse novo cenário, apresentando-se como uma chave para estimular nas pessoas capacidades e atitudes que as tornem cidadãs participativas, provocando, assim, mudança interior que as habilite a conhecer suas próprias habilidades, antes ignoradas, capacitando-as a provocar as mudanças no exterior, ou seja, no mundo.

O curso Desenvolvimento da Capacidade Empreendedora na Terceira Idade teve como objetivo oferecer às pessoas dessa faixa etária a oportunidade de participar de um programa que lhes permitisse adquirir, rever e ampliar conhecimentos, na área do empreendedorismo. Durante o período do curso, os participantes puderam expressar suas habilidades e potencialidades, resgatando a autoestima e a autoconfiança. Foram oferecidas informações que possibilitaram a descoberta de habilidades até então adormecidas e a obtenção de novos conhecimentos, de recursos instrumentais e emocionais, a fim de que pudessem viver, pensar, sentir e agir de forma a acompanhar as rápidas mudanças pelas quais o mundo está passando (IRIGARAY, SCHNEIDER, 2008).

Embora o tema seja atual, poucos são os programas que apoiam a inclusão, capacitação e formação empreendedora nessa faixa etária. Assim, além de evidenciar que uma instituição de ensino tem função social muito importante no desenvolvimento de novos conhecimentos e aprimoramento de práticas existente, colaborando com a necessidade de desenvolvimento da sociedade na era do conhecimento, este trabalho explicita a importância do desenvolvimento da capacidade empreendedora na terceira idade.

\section{REFERENCIAL TEÓRICO}

\subsection{Conceitos básicos}

Este referencial teórico aborda os conceitos básicos inerentes ao assunto que está sendo tratado. 
O empreendedorismo surgiu ligado à ideia militarista de estratégia, mas logo se voltou ao desenvolvimento econômico, tomando como partida, segundo Souza (1997), as ações inovadoras, considerando as constantes transformações derivadas do meio socioeconômico e, sobretudo, das inovações tecnológicas que repercutem no dinamismo dos mercados, motivando a um contínuo processo de adaptação.

Hoje o empreendedorismo pode ser visto, conforme Brazeal e Herbet (1999), associado à inovação para desenvolver novos meios de visualizar velhos problemas (criatividade) ou provocar novas necessidades, problemas ou processos complementares aos existentes (mudanças). Assim, o termo está associado à criatividade, persistência, realização de objetivos, liderança, iniciativa, flexibilidade, habilidade, etc., impulsionando mudanças econômicas e sociais e criando novas formas para fazer as coisas (DEES, 1998).

Schumpeter (1983) apresenta o empreendedor como agente do processo de destruição criativa que impulsiona o motor da economia e cria novos produtos. Já Drucker (1986) traz a visão de que o empreendedor tem a capacidade de explorar as oportunidades criadas pela mudança, portanto, busca as fontes de inovações e cria oportunidades. Isso o torna atrativo, tanto ao setor social, como comercial, industrial ou organizacional.

Timmons e Spnelli (2004) afirmam que o empreendedor é uma máquina de geração de oportunidades.

Vidal (2003) caracteriza o empreendedor como uma pessoa criativa, marcada pela capacidade de estabelecer e atingir objetivos, e que mantém alto nível de consciência do ambiente em que vive, usando-a para detectar oportunidades.

Por fim, essas características de inovação, visão de oportunidade e criatividade são frutos de um aprendizado contínuo, que faz parte da vida e da personalidade de um empreendedor.

\subsection{Terceira idade}

Hayflic (1996) afirma que o envelhecimento é a manifestação dos eventos que ocorrem ao longo de um período de tempo e que acontece de forma diferente entre as pessoas. É um processo múltiplo e complexo de contínuas mudanças ao longo do curso da vida, influenciado pela integração de fatores sociais e comportamentais. Assim, o idoso pode ser visto como uma pessoa vivida, com muita sabedoria e inteligência para lidar com os problemas do dia a dia. Pacheco (2002) diz que é o resultado de dois processos: o processo primário, que é intrínseco ao organismo, e o secundário, causado por fatores ambientais que 
afetam de forma diferenciada as mudanças fisiológicas, anatômicas, hormonais e bioquímicas do organismo.

Ter a consciência de que a população brasileira de idosos tem crescido nos últimos anos e refletir sobre o que pode estar afetando o idoso, no que se refere à situação econômica, social, psicológica e à perda de contato com a força de trabalho, torna-se necessário. Nesse sentido, Mercadante (1998) faz referência à sociedade que restringe o idoso, reduzindo-o a um mundo limitado. Um desses lugares, densamente valorizado, é aquele relativo ao mundo produtivo, o mundo do trabalho.

Segundo Barros (1998), os critérios e normas da idade cronológica são impostos na sociedade ocidental por exigência das leis que determinam os deveres e direitos do cidadão. Assim, terceira idade é uma categoria socialmente produzida, independente da relação de estrutura biológica e incorporação dos estágios de maturidade dos indivíduos. O equilíbrio psíquico do idoso depende da adaptação a sua existência presente e passada e das condições da realidade que o cercam.

Segundo dados da OPAS/OMS (2005), até 2025 o Brasil será o sexto país do mundo com o maior número de pessoas idosas. Daí o alerta ao governo brasileiro para a necessidade de serem criadas, o mais rápido possível, políticas sociais que preparem a sociedade para essa realidade, abrindo horizontes para um envelhecimento com expectativa de uma vida saudável e com qualidade. Todavia, poucas escolas no país criaram ou criam cursos para auxiliar as pessoas mais velhas. A Constituição de 1988, no entanto, deixou clara a preocupação e atenção que devem ser dispensadas ao idoso, constituindo-se no pontapé inicial para a definição da Política Nacional do Idoso, através da Lei 8.842, de 4 de janeiro de 1994, que traçou os direitos desse público e as linhas de ação setorial. Com isso as instituições de ensino superior passaram a se adaptar, com a criação de cursos de Geriatria e Gerontologia. Mas é necessário mais.

\subsection{Empreendedorismo na terceira idade}

Estamos frente a grandes mudanças, novas posturas, tecnologias, tendências, perfis organizacionais, pessoas, sociedades, comunicações e mercados. Nesse cenário, as capacidades empreendedoras podem ser entendidas, segundo Birley e Muzika (2001), como competências para solucionar problemas e necessidades, que podem ser vistas como fontes de oportunidades para mudanças. A maior parte das oportunidades viáveis surge de problemas, necessidades e mudanças (SCHMITZ, 2009). As mudanças, conforme Drucker (1986), 
provavelmente ainda são as melhores fontes de oportunidades com grandes chances de sucesso.

Portanto, a capacidade empreendedora pode ser vista como resultado da soma de fatores inatos, interação com a família, com a sociedade, experiências de vida, interação com grupos de trabalho, religiosos e recreativos, os quais são necessários para o processo de criação do conhecimento pessoal e organizacional (NONAKA; TAKEUCHI, 1997). As condições capacitadoras para criação de um ambiente inovador consideram indicadores como energia uma centelha criativa, que só pode ser ativada pelo indivíduo que teve um insight. Nesse sentido, as fronteiras das pessoas se alargam, e suas capacidades empreendedoras aumentam à medida que trocam experiências ou desenvolvem novas ideias. Pensando nisso, idealizou-se o curso "Desenvolvimento da Capacidade Empreendedora na Terceira Idade", no NETI/UFSC.

\subsection{Ensinando o empreendedorismo}

Segundo Barbosa e Santos (2001), as relações de emprego sofreram grandes alterações nas últimas décadas. O avanço da tecnologia e a necessidade de as empresas serem cada vez mais competitivas, aliados à conjuntura socioeconômica, diminuíram vertiginosamente os postos de trabalhos tradicionais. Essa redução explicita a necessidade de criação de um novo perfil profissional, destinado a ocupar um espaço nesse mercado: o empreendedor. A educação transformou-se numa grande aliada na inserção do trabalhador no mercado de trabalho. Nesse sentido Thurow $(2001$, p. 96) afirma que:

\footnotetext{
O conhecimento gera os grandes avanços básicos de tecnologia. O conhecimento permite que, de um momento para outro, coisas novas sejam feitas de novas maneiras [...] Velhas atividades podem ser executadas de maneiras tão diferentes que elas se transformam essencialmente em novos produtos.
}

Com relação ao empreendedorismo, não basta a transmissão do conhecimento, é necessário estimular e desenvolver atitudes mais empreendedoras nos alunos (SAMPAIO, MASMO, 2008). Portanto, cabe às instituições educacionais contribuir para o desenvolvimento da educação empreendedora. Nesse cenário educacional está a terceira idade. Com o aumento da expectativa de vida, as pessoas começam a olhar para essa etapa de outra forma, já que o período após a aposentadoria se torna cada vez mais longo. Assim, o empreendedorismo cumpre um importante papel nessa fase da vida de muitas pessoas, estimulando e incentivando a visão para oportunidades. 
A institucionalização do curso de vida envolve as dimensões do mundo familiar e do trabalho, além de estar presente na organização do sistema produtivo, nas instituições educativas, no mercado de consumo e nas políticas públicas, as quais têm, cada vez mais, como alvo, grupos etários específicos. Está presente do nascimento até a morte, passando por um sistema complexo que engloba as fases de escolarização, entrada no mercado de trabalho e aposentadoria. (LOPES, 2000).

Toda cultura absorvida da era industrial ainda é sentida nos dias de hoje. Segundo Pacheco (2002), pode-se observar que a tecnologia leva à criação de espaços urbanos de produção nos quais os jovens são absorvidos, e os mais velhos tornam-se rapidamente obsoletos, e seus conhecimentos desvalorizados; a urbanização acelerada aumenta a segregação entre gerações deteriorando os laços familiares e contribuindo para a redução da importância conferida aos mais velhos. Por outro lado, a tecnologia na saúde acrescenta anos à expectativa de vida, gerando uma competição geracional pelo mercado de trabalho, no qual os idosos são empurrados para os cargos de menor renda e menor prestígio (PACHECO, 2002).

$\mathrm{Na}$ era do conhecimento, as ocupações se transformam em mais criativas e menos mecânicas. As mudanças introduzidas no trabalho o tornam mais criativo, exigindo das pessoas capacidades de decisão para constantes redirecionamentos de questões que se encontram em constantes e velozes mudanças. Nesse sentido, a ocupação na terceira idade envolve gestões mais participativas. As pessoas com mais idade, amadurecidas, com grande potencial de suas vivências e com grande bagagem cognitiva, embora possam apresentar limitações físicas, tornam-se estratégicas pelo desempenho de seus conhecimentos tácitos.

A terceira idade, considerando a inserção na atividade empreendedora, segundo Almada (2001), mostra o desenvolvimento da cultura empreendedora para a educação da terceira idade diante do crescente desafio de novos empreendimentos para essa faixa etária. Em geral, a pessoa da terceira idade sente a necessidade de ser valorizada dentro da sociedade, portanto, deseja voltar à situação de trabalho, uma vez que hoje o ser qualificado é o trabalhador. Assim, ocupações vinculadas ao autoemprego e às oportunidades de trabalho advindas do empreendedorismo serão as novas oportunidades.

\subsection{Núcleo de Estudos da Terceira Idade (NETI/UFSC)}

As primeiras ideias sobre o trabalho com pessoas idosas na Universidade Federal de Santa Catarina (UFSC) surgiram em março de 1982. Em 3 de agosto de 1983, foi oficialmente 
criado, através da Portaria 0484/GR/83, assinada pelo reitor Ernani Bayer, o Núcleo de Estudos da Terceira Idade, órgão vinculado ao Departamento de Projetos de Extensão da PróReitoria de Pesquisa e Extensão da Universidade Federal de Santa Catarina.

A partir de então a UFSC vem confirmando seu interesse em participar efetivamente do esforço nacional em prol do envelhecimento sadio e, por meio do NETI, desencadeia um processo educacional em que o idoso é protagonista de seu próprio envelhecer. No decorrer desses anos, vem se mantendo fiel aos princípios de valorizar a pessoa idosa inserindo-a no contexto acadêmico e comunitário, com o objetivo de: (i) ampliar e sistematizar o conhecimento da gerontologia; (ii) formar recursos humanos; (iii) manter atividades interdisciplinares de ensino, pesquisa e extensão; (iv) divulgar e desenvolver ações institucionais e interinstitucionais; (v) assessorar entidades na organização de programas de valorização do idoso; (vi) oferecer subsídios para uma política de resgate do papel do idoso na sociedade; e (vii) realizar treinamentos, palestras e consultorias na área gerontológica.

O NETI desperta o idoso para a ação renovadora na área gerontológica e busca transformá-lo em agente por excelência para ajudar a equacionar as questões sociais brasileiras. Pauta suas atividades em princípios pelos quais o homem é um ser que se realiza no mundo e pode aprender durante toda a sua existência, desenvolvendo atividades de

promoção no meio acadêmico e comunitário, como sujeitos em transformação e transformadores. É um setor de referência para estudos de graduação e pós-graduação e ainda desenvolve vários cursos de capacitação para os idosos.

O curso intitulado "Desenvolvimento da Capacidade Empreendedora na Terceira Idade" foi realizado nos anos de 2008 e 2009, contou com a participação de 24 alunos e teve o objetivo de despertar capacidades empreendedoras nos participantes, a partir de suas habilidades pessoais, por meio da aplicação de aulas participativas, visando ao aprimoramento da teoria e da prática empreendedora na terceira idade.

\section{METODOLOGIA}

A metodologia da pesquisa perpassou por atividades de aulas com duas horas semanais, realizadas às segundas-feiras, em local previamente determinado. Nesse período os alunos participaram de exposições teóricas, aplicações de técnicas vivenciais, seminários e palestras, os quais abordaram temáticas da atualidade e realidade do empreender no contexto organizacional e social. 
O estudo realizado foi do tipo exploratório, uma vez que o propósito básico foi buscar informações sobre o comportamento do empreendedor na terceira idade. A pesquisa foi conduzida em uma instituição de ensino superior, localizada na cidade de Florianópolis, e caracterizou-se por uma pesquisa ação e estudo de caso. A coleta dos dados se deu através da aplicação de questionários, inicial e final, aos alunos das duas turmas do curso Desenvolvimento das Capacidades Empreendedoras na Terceira Idade, do NETI/ UFSC, nos anos de 2008 e 2009, com perguntas fechadas e semiabertas.

O universo de alunos matriculados nas duas turmas foi de 28 alunos, resultando numa amostra de 24 alunos que concluíram o curso. Os métodos utilizados para realização do curso passaram por adaptações necessárias ao tipo de público participante. Ainda, no segundo questionário aplicado aos participantes, constava uma pergunta cujo objetivo era obter um feedback em relação ao curso ministrado. O primeiro questionário era formado por seis questões e foi aplicado durante a primeira aula. $\mathrm{O}$ segundo foi aplicado durante a última aula e continha duas questões, as quais solicitavam aos participantes uma descrição de suas percepções quanto ao curso e à relação com seus aprendizados para suas vidas. Os dados foram descritos de forma a possibilitar a compreensão da adaptação e evolução dos participantes nas atividades desenvolvidas e o entendimento deles em relação ao empreendedorismo.

\section{RESULTADOS}

Vinte e quatro alunos que frequentaram as duas turmas do curso Desenvolvimento da Capacidade Empreendedora na Terceira Idade responderam aos questionários. Estes representam 85,71\% dos alunos matriculados no curso, de um total de 28 alunos do NETI/UFSC. Dessa amostra, 19 são mulheres e cinco são homens, com idade entre 51 e 79 anos.

A primeira pergunta do questionário inicial solicitou aos participantes que elencassem características empreendedoras conforme percepção pré-curso. Dentre as características de um empreendedor, foram destacadas, no questionário inicial: criatividade, com 6 respondentes ou 25\%; correr risco e liderança, com 5 respondentes ou 20,84\%; desafio e inovação, com 3 respondentes ou 12,50\%; conhecimento e ação, com 2 respondentes ou 8,33\%; e visão, comunicação, planejamento e realização pessoal, com 1 respondente ou 4,16\%. 
As respostas da questão número 1 representam a visão de empreendedorismo, conforme a percepção pré-curso dos participantes. Dolabela (1999), em seu livro O segredo de Luísa, apresenta várias das características apontadas pelos participantes do curso. Foram apresentadas as prevalências das características conforme indicado nos questionários dos alunos respondentes, considerando que houve duplicidade nas respostas dos participantes.

O questionário inicial, em sua questão de número 2, contemplou quatro alternativas que poderiam ter múltipla escolha, o que está representado na Tabela 1.

Tabela 1: Motivos pessoais para realização do curso

\begin{tabular}{l|l|l}
\hline Motivo & $\mathbf{N}$ & $\mathbf{\%}$ \\
\hline Interesse pelo tema & 12 & 50 \\
\hline Interesse em conhecimento p/vida particular & 09 & 37,50 \\
\hline Interesse em conhecimento p/aplicação no trabalho & 05 & 20,83 \\
\hline Interesse em desenvolver novas atividades & 15 & 62,50 \\
\hline
\end{tabular}

As respostas contidas na Tabela 1 representam o que motivou os participantes a realizarem o curso no NETI/UFSC. Considerou-se a duplicidade de respostas por serem questões de múltipla escolha. Entre os motivos mais frequentes, encontram-se o interesse pelo tema e a busca por novos conhecimentos.

Ainda quanto ao questionário inicial foi indagado, na terceira questão, o que o aluno esperava do curso. Tratava-se de uma questão aberta cuja finalidade era provocar respostas que alavancassem a condução do curso a fim de atender às expectativas dos participantes.

A questão apresentou respostas variadas, com uma maior prevalência para a necessidade de aquisição de conhecimento, 16 respondentes, ou $66,66 \%$, e para a necessidade de realização pessoal, que teve 2 respondentes, ou 8,33\%. Essas respostas apontam a perspectiva pessoal de cada participante, mas, ao mesmo tempo, não trazem informações quanto a adaptações, alterações ou mudanças, sugeridas por eles, para o curso.

Dolabela (2003), ao tratar da "Pedagogia Empreendedora", sugere a necessidade de se implementar essa metodologia na educação básica e infantil, pois estimula a capacidade de escolha, de decisão e prepara os alunos para suas próprias opções e, em face da realidade das pessoas nessa faixa etária, observa-se a necessidade desse tipo de aprendizagem, a fim de possibilitar e desenvolver suas capacidades empreendedoras.

Ainda quanto a essa expectativa para o curso, no questionário final, por meio de questão aberta, novamente provocou-se o público-alvo. Procurou-se saber se o curso alavancou a expectativa inicial, bem como foram solicitadas sugestões para eventuais mudanças na condução das aulas e melhorias que pudessem ser efetuadas.

Extensio: R. Eletr. de Extensão, ISSN 1807-0221 Florianópolis, Ano 8, n. 12, p. 109-121, 2011. 
Dos respondentes, 91,66\% (22) disseram que alcançaram o que procuravam com o curso, alegando diversos motivos como: o curso trouxe motivação; foi um curso dinâmico; trouxe uma nova visão; ampliou nossos horizontes de possibilidades. No entanto, os respondentes não trouxeram novas sugestões, tampouco apresentaram críticas quanto ao método empregado, sugerindo satisfação quanto ao método aplicado.

Além de responderem que o curso alavancou a expectativa inicial de aquisição de conhecimento, os participantes ressaltaram também a aquisição de novos conhecimentos. Relataram ainda que o curso proporcionou: (i) maior alegria e prazer em viver; (ii) preenchimento do tempo com atividades prazerosas e conquista de um novo sentido de vida; (iii) vontade de realizar; (iv) participação e predisposição para a inovação e proatividade. Por ter sido uma questão aberta, algumas respostas foram coincidentes.

O questionário final também fez as seguintes indagações aos participantes: Você se considera um empreendedor? Se você se considera, responda por que. 95,33\% (23) responderam que se consideravam empreendedores e apresentaram as características pessoais que os fazia ter esse tipo de percepção. As respostas apresentadas também se repetiram, porque a indagação possibilitava uma livre reflexão. Somente 4,67 \% (01) não se consideraram empreendedores por não terem respondido à pergunta.

Ainda, nas suas exposições e reflexões, alguns expuseram que se consideravam persistentes, pois obtinham final feliz em tudo que realizavam. Alguns disseram que iam à luta, que empreendiam no dia a dia. Essas respostas possibilitaram observar que os participantes conseguiram entender o espírito do curso: despertar as virtudes e características adormecidas ou encobertas, as quais passaram a relatar. Essa também foi uma questão aberta, daí algumas respostas serem coincidentes.

Por ser considerada uma forma de pensar e agir, a educação para o empreendedorismo é abordada por autores como Dolabela (2003), Drucker (1986), Filion (1991), Shepherd (2004), Souza et al. (2005), Souza e Guimarães (2005).

Por último, a Tabela 2 apresenta as respostas dos alunos após os dois meses de aula. A expectativa nessa resposta, para os organizadores do curso, era poder identificar ou não uma evolução nos alunos quanto à visão, ao entendimento e à percepção sobre o empreendedorismo, e o que poderia ter despertado neles essa nova visão. 
Tabela 2 - Características empreendedoras após a realização do curso

\begin{tabular}{l|l|l}
\hline Respostas & $\mathrm{N}$ & $\%$ \\
\hline Persistência para realizar os sonhos & 15 & 62,50 \\
\hline Definir metas & 12 & 50 \\
\hline Planejar & 9 & 37,50 \\
\hline Ter foco & 5 & 20,84 \\
\hline Ter iniciativa & 5 & 20,84 \\
\hline Correr riscos calculados & 3 & 12,50 \\
\hline Trabalhar em grupo & 2 & 8,33 \\
\hline Buscar o novo & 2 & 8,33 \\
\hline
\end{tabular}

Além de os respondentes terem a opção de múltipla escolha, podiam fazer um comentário após a resposta, no espaço reservado para as observações. A Tabela 2 mostra que muitos conceitos tratados no transcorrer do curso foram despertados nos alunos. Além disso, eles acrescentaram às observações o despertar de definição de metas e relato de sonhos, o que possibilitou observar que, para despertar o empreendedor que há em cada um, em muitas ocasiões, é necessária a realização de cursos sobre empreendedorismo para essa faixa etária, confirmando o referencial teórico.

\section{CONSIDERAÇÕES FINAIS}

O curso trouxe um novo enfoque sobre empreendedorismo para os seus participantes. A motivação baseou-se na vontade de realizar, que é uma das características apontadas na literatura como essenciais para o empreendedor.

Realização foi palavra de ordem dos alunos do curso de empreendedorismo do NETI/UFSC. Além de se sentirem motivados para novas realizações e expectativa de vida produtiva, eles tiveram a percepção de que os obstáculos podem ser enfrentados com as características de um empreendedor.

Após análise dos dados coletados, foi possível constatar que o perfil do empreendedor na terceira idade está, em sua maioria, na satisfação pessoal, uma vez que, na declaração dos alunos, na terceira idade é necessário que o empreendedor empreenda a si mesmo. Além disso, com a realização da dinâmica e sensibilização da última aula, colheram-se dos alunos declarações quanto às expectativas que o curso lhes causou. Isso possibilitou uma visão diferente da inicial, pois suscitou um espírito de vida e possibilidades de realização.

Conclui-se que o objetivo do curso foi alcançado, tendo em vista a avaliação positiva feita pelos participantes por meio de questionário aplicado no início e no final das atividades didáticas desenvolvidas. Também foi salientada a importância do estímulo ao 
empreendedorismo nessa faixa etária, além da notória alteração das atitudes com mais participação e predisposição para a inovação.

As respostas dos participantes indicaram a tendência a valorizar a vida com a busca de conhecimentos, realização ou satisfação pessoal, busca do novo, desafio para o desconhecido, busca de novos horizontes para a prática profissional e colocação em prática de ideais de vida. A proatividade ficou estampada no comportamento pessoal com definição de metas e relato de sonhos empreendedores.

\section{REFERÊNCIAS}

ALMADA, Clineu. Terceira idade. Censo 2000. Jornal Valor. São Paulo.2001 Disponível em: $<$ http://www.valoronline.com.br>. Acesso em 15 de nov. 2008.

BARBOSA, Jenny D.; SANTOS, Rosinadja B. Ensino de empreendedorismo: uma alternativa para a formação do administrado. In: XII ENCONTRO NACIONAL DOS CURSOS DE GRADUAÇÃO EM ADMINISTRAÇÃO: 12, 2001 Florianópolis. Anais... Florianópolis: Enangrad, 2001 - [Fatores críticos no ensino de graduação em administração].

BARROS, Myriam Moraes LINS de (ORG.). Velhice ou terceira idade? Estudos antropológicos sobre identidade, memória e política. Rio de Janeiro: Fundação Getúlio Vargas, 1998.

BIRLEY, Sue; MUZIKA, Daniel F. Dominando os desafios do empreendedor. São Paulo: Makron Books, 2001.

BRASIL. Lei 8.842, de 04 de janeiro de 1994. Dispõe sobre a política Nacional do Idoso, cria o Conselho Nacional do Idoso e dá outras providências. Disponível em HTTP://www.planalto.gov.br/ccivil 03/Leis/L8842.htm. Acesso em 15 nov.2008.

BRAZEAL, Deborah V. \& HERBET, Theodore T. The genesis of entrepreneurship.

Entrepreneurship Theory and Practice, Oxford, v.23, n.3, p.29-45, Spring 1999.

DEES, Gregory J. O Significado de empreendedorismo social. 1998. Disponível em

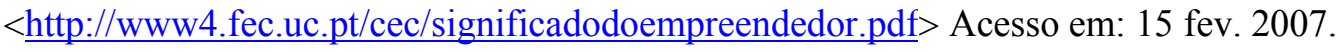

DOLABELA, Fernando. O Segredo de Luísa. São Paulo: Cultura, 1999. 320p.

DOLABELA, Fernando. Pedagogia empreendedora. São Paulo: Cultura, 2003. 144p.

DRUCKER, Peter F. Inovação e espírito empreendedor: prática e princípios. São Paulo: Pioneira, 1986.

FILION, Louis Jacques. O planejamento do seu sistema de aprendizagem empresarial: identifique uma visão e avalie o seu sistema de relações. Revista de Administração, v. 31, n. 3, p. 63-71, jul./set. 1991.

HAYFLIC, Leonard. Como e porque envelhecemos. Rio de Janeiro: Campus, 1996.

IRIGARAY, Tatiana Quarti; SCHNEIDER, Rodolfo Herberto. Participação de idosas em uma universidade da terceira idade: motivos e mudanças ocorridas. Psic.: Teor. e Pesq. Brasília, v.24, n.2, abr.jun. 2008 .

Extensio: R. Eletr. de Extensão, ISSN 1807-0221 Florianópolis, Ano 8, n. 12, p. 109-121, 2011. 
LOPES, Andréa. A Sociedade Brasileira de Geriatria e Gerontologia e os desafios da gerontologia no Brasil. 2000 Dissertação (Mestrado em Gerontologia) Programa de Pós Graduação em Engenharia de Produção, Universidade Estadual de Campinas, São Paulo, 2000.

MERCADANTE, Elizabeth Frohlich. A identidade e a subjetividade do idoso. Revista Kairós, Núcleo de Estudo e Pesquisa do Envelhecimento. Programa de estudos pós-graduados da PUC/SP São Paulo, v.1, n.1, p. 59-67, 1998.

NONAKA, Ikujiro; TAKEUCHI, Hirotaka. Criação de conhecimento na empresa: como as grandes empresas japonesas geram a dinâmica da inovação. Rio de Janeiro: Campus, 1997.

OPAS/OMS - ORGANIZAÇÃO PAN-AMERICANA DA SAÚDE. Envelhecimento ativo: uma política de saúde. Tradução: Suzana Gontijo. Brasília: OPAS/OMS, 2005

PACHECO, Jaime Lisandro. Educação, trabalho e envelhecimento: estudo das histórias de vida de trabalhadores assalariados focalizando as relações com a escola, com o trabalho e com os possíveis sintomas depressivos, após a aposentadoria. Tese (Doutorado em Educação) Faculdade de Educação, Universidade Estadual de Campinas. São Paulo, 2002.

SAMPAIO, Mara Elaine de Castro; MASMO, Patrícia Luissa. Educação e cultura empreendedora: a preparação do corpo docente de uma instituição de ensino profissionalizante no Estado de São Paulo. XIX CONGRESO LATINOAMERICANO Y DEL CARIBE SOBRE EL ESPÍRITU EMPRESARIAL. 19 Florianópolis. Anais... Florianópolis: CLEE, 2008. [Nuevas Empresas En Un Nuevo Mundo].

SCHMITZ, Ana Lúcia F. Falta de oportunidade! Quem disse? Onde está o empreendedor? Florianópolis: Pandion, 2009.

SCHUMPETER, Joseph A. Teoria do desenvolvimento econômico. São Paulo: Abril Cultural, 1983.

SHEPHERD, Dean A. Educating students about emotion and learning from failure. Academy of management Learning \& Education, New York, v.3,n.3, p 274-288, 2004.

SOUZA, Nali de Jesus de. Desenvolvimento econômico. 3 ed. São Paulo: Atlas, 1997.

SOUZA, Eda Castro Lucas et al. Métodos, técnicas e recursos didáticos de ensino de empreendedorismo em IES brasileiras. In: SOUZA,E.C.L.; GUIMARÃES, T.A., Empreendedorismo além do plano de negócio. São Paulo: Atlas, 2005.

SOUZA, Eda Castro Lucas; GUIMARÃES, Tomás de Aquino. O Ensino de empreendedorismo em instituições de ensino superior brasileiras. In: SOUZA, E.C.L.; GUIMARÃES, T.A.,

Empreendedorismo além do plano de negócio. São Paulo: Atlas, 2005.

THUROW, Lester C. A construção da riqueza: as novas regras para os indivíduos, empresas e nações numa economia baseada no conhecimento. Rio de Janeiro: Rocco, 2001.

TIMMONS, Jeffrey A.; SPINELLI, Stephen. New adventure creation: entrepreneurship for the $21^{\text {st }}$ century. Boston: Irwin McGraw Hill, 2004.

VIDAL, Francisco. Empreendedorismo social e economia social e economia solidária: um estudo de caso da rede DLIS de uma comunidade na cidade de Fortaleza. In: CONGRESSO LATINO

AMERICANO DE ADMINISTRAÇÃO. Lima. Anais... Lima: CLADEA, 2003. 